\title{
Financial scarcity undermines health across the globe and the life course $\mathrm{i}^{\text {is }}$
}

\author{
Nicolas Sommet ", Dario Spini \\ LIVES Center, University of Lausanne, Switzerland
}

\section{A R T I C L E I N F O}

\section{Keywords:}

Financial scarcity

Health

Well-being

Sense of control

Life events

\begin{abstract}
A B S T R A C T
The gradient between income and health is well established: the lower the income, the poorer the health. However, low income (having few economic resources) may not be enough to characterize economic vulnerability, and financial scarcity (perceiving having insufficient economic resources) may further reduce health. First, analysis of cross-national data (275,000+ participants from $200+$ country-years) revealed that financial scarcity was associated with twice the odds of suffering from reduced self-rated health and feelings of unhappiness; this association was observed in $\approx 90 \%$ of the country-years and explained variance over and above income. Second, analysis of national longitudinal data $(20,000+$ participants over 20 years of assessment) revealed that facing financial scarcity in the course of one's life decreased self-rated and objective health and increased feelings of depression; again, these effects explained variance over and above income. Two subsidiary findings were obtained: (i) three adverse life events (illness, separation, family conflicts) predicted financial scarcity over the life course, and (ii) self-mastery (a component of sense of control) accounted for the detrimental longitudinal effects of financial scarcity on health. This research suggests that to understand socioeconomic inequality in health, one should consider not only an individual's quantity of monetary resources but also the perceived sufficiency of these resources.
\end{abstract}

Over the past thirty years, household debt has risen to unprecedented levels in most developed and developing economies (Hays, 2018). For instance, between the mid-1990s and the mid-2010s, the mean household income-to-debt ratio in OECD countries increased from $70 \%$ to a record high of $130 \%$, meaning that households now have more debt than annual income (Bolibok, 2018). As another example, in 2020, credit-card debt in the U.S. reached $\$ 1098$ trillion (the highest level in the history of the country), which roughly corresponds to $\$ 8000$ in revolving debt per household (FED, 2020).

Whereas having low monetary resources is well known to harm health (the income-health gradient; Chetty et al., 2016), having insufficient monetary resources and being mired in debt (financial scarcity) may carry an additional psychological cost and further reduce both general and psychological health. In this paper, we investigated the worldwide and life-course association between financial scarcity and health (the "what" question). In addition, we raised two subsidiary research questions: (i) When do individuals experience financial scarcity? and (ii) Why is financial scarcity associated with poor health?

\section{The gradient between income and health}

The gradient between income and health is well established. Decades of research have shown that there is a positive linear relationship between income categories and health (Adler et al., 1994). Recently, a large-scale American study including $\approx 1.5$ billion observations showed that the graded association between income percentile and mortality was such that the gap in life expectancy between the top $1 \%$ and bottom $1 \%$ of income earners was approximately 10 years for women and 15 years for men (Chetty et al., 2016). Compared to high-income individuals, low-income individuals have a twofold increased risk of developing cardiovascular disease (Karlamangla et al., 2010), a lower survival rate for the most common cancers (Coleman et al., 2004), and a higher prevalence of chronic pulmonary diseases (Sahni et al., 2017).

Income not only impacts physical morbidity and mortality but also reduces subjective well-being and psychological health (Kahneman and Deaton, 2010). Another large-scale American longitudinal study documented a graded effect of income quartile on suicide attempts, with 20to 54-year-old participants in the lowest income quartile being 3.5 times more likely to report having attempted suicide than participants in the

\footnotetext{
Nicolas Sommet, Dario Spini, NCCR LIVES, University of Lausanne, Switzerland.

* Corresponding author. Bâtiment Géopolis, Bureau \#5785, Quartier UNIL-Mouline, Université de Lausanne, Switzerland.

E-mail address: nicolas.sommet@unil.ch (N. Sommet).
} 
highest income quartile (Sareen et al., 2011). Compared to high-income individuals, low-income individuals are more likely to suffer from schizophrenia (Agerbo et al., 2015), major depression (Lorant et al., 2003), and anxiety disorders (Cheng et al., 2015).

Two main mechanisms account for the income-health gradient (Adler and Snibbe, 2003). First, low-income individuals tend to live in unhealthier environments than high-income individuals (the material pathway). Low-income individuals are more likely to reside in unsafe communities (Kang, 2016), to be exposed to occupational hazards (Evans and Kim, 2010), and to have limited access to health care (Van Doorslaer et al., 2006). Second, low-income individuals tend to lead more stressful lives than high-income individuals (the psychosocial pathway). Simply put, they tend to suffer from higher chronic financial stress, which accumulates over the course of their lifetimes and causes "wear and tear" on their bodies and especially their minds (Garrison and Rodgers, 2019).

With respect to the second mechanism, one may wonder whether income allows one to fully capture the extent to which individuals experience such damaging chronic financial stress. Income refers to an amount of actual economic resources that one lacks or holds. However, a low amount of economic resources does not necessarily mean that one is defenseless, insecure, or exposed to risks, shocks, and stress (Chambers, 1989). For instance, one may imagine an individual in the lowest income quintile living such a modest life that their limited income would not be a source of chronic financial stress and, by extension, undermine health. Conversely, one may imagine an individual in a higher income quintile having to deal with an unexpected life event, such as an illness or a divorce, and suddenly becoming economically vulnerable. In this research, we argue that considering financial scarcity as an incremental marker of socioeconomic position could help obtain a better grasp of economic vulnerability.

\section{Financial scarcity}

Mullainathan and Shafir (2014) defined financial scarcity as a subjective sense of having less than one feels they need stemming from situations in which one has too little "to cover the mortgage, car payments, and day-to-day expenses" (pp. 4-5). Contrary to income, financial scarcity hinges on the insufficiency (rather than the quantity) of one's monetary resources. Specifically, individuals enter a financial scarcity mindset when they perceive that they have fewer monetary resources than their monthly expenses require (they spend savings and/or borrow money). However, individuals enter a financial equilibrium mindset when they perceive they have barely an adequate amount of monetary resources to meet their monthly daily expenses (they just get by), and they enter a financial abundance mindset when they perceive they have more monetary resources than their monthly expenses require (they save money).

Most of the research in this field has come from experimental behavioral economics and examines the double-edged cognitive effects of financial scarcity (for a review, see Hamilton et al., 2019). On the one hand, research indicates that financial scarcity leads to a focusing effect: Participants induced with scarcity tend to devote their full attention to the task at hand and become more efficient in managing trade-offs (Shah et al., 2012). In a real-world setting, this means that households facing financial scarcity have no choice but to make the most of their limited resources, so much so that they actually become better at managing their budgets in the short term.

However, experimental research indicates that financial scarcity leads to a tunneling effect: Since participants induced with scarcity confine their attention to cues that are central to the task at hand, they tend to neglect other peripheral-but no less important-elements, which leads to prejudicial attentional narrowing (Tomm and Zhao, 2016) and present-biased economic decisions (Carvalho et al., 2016). In a real-world setting, this means that households facing financial scarcity are exposed to chronic financial stress that taxes attentional bandwidth and leads to myopic behaviors, overborrowing, and economic decisions that ironically perpetuate their conditions of scarcity (the "scarcity trap"). Herein, we argue that the sense of constant financial urgency and loss of control induced by financial scarcity may not only cause attentional deficits but also affect health.

\subsection{What are the effects of financial scarcity on health?}

Two studies tested the link between financial scarcity and health. The first study used data from the Netherlands $(N \approx 3000$ participants) and showed that respondents who did not have enough money to get through the month were almost four times more likely to suffer from a depressive and/or anxiety disorder than respondents who usually had money left at the end of the month (Dijkstra-Kersten et al., 2015). The second study used data from 40 countries $(N \approx 150,000$ participants) and showed that respondents who had to spend savings and/or borrow money to survive financially reported lower levels of mental well-being than participants who were able to save money (Sommet et al., 2018).

However, these two studies were limited in four important ways. First, the two studies focused only on mental health and did not take general health into consideration. Second, the two studies did not partial out the variance explained by the income-health gradient when estimating the scarcity-health link. Third, the two studies did not include subjective SES (socioeconomic status) as a covariate, although it is known that objective and subjective SES explain independent variance in health (Präg et al., 2016). Fourth, the two studies did not address the question of the predictors of financial scarcity (the "when" question) or investigate the psychological processes through which financial scarcity altered health (the "why" question).

\subsection{When do individuals experience financial scarcity?}

To understand the roots of economic vulnerability, many authors have stressed the importance of adopting a life course perspective (e.g., Pearlin et al., 2005). Specifically, addressing the issue of economic vulnerability requires studying adverse life events, as the contemporary life course perspective "views vulnerability more as a product of critical life events (e.g., losing one's job or separating from one's spouse), and less as a result of social stratification dynamics" (Spini et al., 2017, p. 17).

There are reasons to believe that financial scarcity is not only driven by between-individual socioeconomic determinants (e.g., nonhomeownership), but also by within-individual life-event determinants (e.g., an illness, a divorce). From a theoretical perspective, when individuals need to recover from an adverse life event, they have to cover unexpected expenditures and draw upon their reserves. In doing so, they are no longer able to accumulate or even maintain these reserves, which further exposes them to vulnerability (Cullati et al., 2018). For instance, we can imagine a middle-class individual becoming critically ill and going into debt to consult a renowned private practitioner or pay the deductible of the insurance policy. Before the illness, this individual was capable of building monetary reserves, but now, sufficient resources are not available to cover monthly expenses, and they feel that they are slowly being pushed into the scarcity trap.

Evidence suggests that adverse life events may magnify existing financial strain or generate new financial strain. In a prospective study, Glickman et al. (1991) asked $\approx 800$ skilled blue-collar workers from the U.S. to list events that had occurred in their lives over the preceding years. They reported that undesirable, disruptive, and unanticipated life events increased financial strain. More recently, specific life events (e.g., a bereavement or family tensions) were found to be associated with increased financial stress and/or decreased ability to keep up with housing payments or to save money (Sturgeon et al., 2014; Taylor, 2009). Thus, it is likely that adverse life events predict financial scarcity across the life course. 


\subsection{Why is financial scarcity associated with poorer health?}

Now that we have discussed when financial scarcity occurs in the life course, we will discuss sense of control as a mechanism accounting for the negative scarcity-health link. It has long been known that sense of control is one of the key psychosocial pathways to health (Pearlin et al., 1981). Believing that one's life is controlled by external factors (the influence of others or luck) rather than determined by one's own actions is thought to cause stress and reduce health. For instance, individuals with a stronger sense of control have a decreased cardiometabolic risk (Infurna and Gerstorf, 2014), a lower mortality rate (Chipperfield et al., 2012), and less anxiety (Gallagher et al., 2014).

Individuals at the bottom of the economic pyramid tend to have fewer opportunities to influence the conditions affecting their day-today lives and feel a lower sense of control (Lachman and Weaver, 1998). We believe that individuals facing financial scarcity should be particularly affected by this reduction in sense of control. The perception of having insufficient monetary resources creates a "focus dividend," whereby the attention system is focused exclusively on the most important demands (e.g., making ends meet at the end of the month). For individuals experiencing financial scarcity, the accumulation of all secondary demands over time (e.g., unexpected expenditures, late payment charges, and spiraling debts) may create the impression of a constant stream of stressors over which they have little, if any, influence. As such, it is likely that they feel that they have only limited personal power over the self (low self-mastery) and/or the environment (low predictability), which may account for why financial scarcity affects their health.

\section{Research questions and overview of the empirical approach}

Our general aim is to estimate the effect of financial scarcity on general and psychological health (the "what" question). Our two subsidiary aims are to test (i) whether adverse life events predict financial scarcity (the "when" question) and (ii) whether a reduction in sense of control is a mechanism accounting for the detrimental longitudinal effects of financial scarcity on health (the "why" question). To address these questions, the present research was conducted in two steps.

First, we combined two large cross-national datasets encompassing more than a quarter of a million participants to estimate the pooled effects of financial scarcity on self-rated health and feelings of unhappiness within $200+$ country-years $^{1}$ (the "what" question). We tested both the raw effects of financial scarcity (without controlling for income) and its incremental effects over and above the income-health gradient, subjective SES, and other demographics.

Second, we used a large national panel dataset following more than 20,000 participants over 20 years of assessment to estimate the longitudinal effects of financial scarcity on self-rated health and feelings of depression. As with the first dataset, we tested both the raw and incremental effects of financial scarcity (the "what" question). Then, we tested whether the occurrence of adverse life events could predict financial scarcity (the "when" question) and whether a reduction in sense of control could account for the detrimental longitudinal effects of financial scarcity on health (the "why" question).

Raw economic data, Stata script files, and instructions to retrieve the data and reproduce the findings are available via the OSF https://osf. io/dkcwg/.

\section{World Value Survey (WVS) and European Value Study (EVS) data}

First, we used the WVS/EVS data to determine the worldwide

\footnotetext{
${ }^{1}$ Country-years are particular national units observed at a particular year (e. g., “Albania-1998”).
}

predictive utility of scarcity for self-rated health and feelings of unhappiness.

\subsection{Method}

\subsubsection{Participants and procedure}

We pooled the responses from the WVS/EVS, a large quinquennial cross-national repeated survey based on a series of national random samples. We applied two inclusion criteria. First, we considered only the country-years for which financial scarcity was assessed (for the list, see Table S1). Second, we retained only participants with nonmissing values for focal variables. Our final sample comprised 278,934 participants from 207 country-years who completed the surveys between 1994 and 2016 (51.76\% women; $M_{\mathrm{age}}=41.08, S D=16.05 ; 53.64 \%$ working; $16.18 \%$ with a university degree; $64.77 \%$ married/cohabiting). A sensitivity analysis revealed that the average sample size per countryyear was sufficient to detect a small-sized effect of financial scarcity $\left(f^{2}=0.01\right)$ in $83.33 \%$ of the country-years with $p<.05$.

\subsection{Variables}

\subsubsection{Predictor variables}

Financial scarcity. Participants answered the following question: "During the past year, did your family (1) save money, (2) just get by, (3) spent some savings, or (4) spent savings and borrowed money." The first option corresponded to financial abundance (resources are insufficient to cover expenses; $24.59 \%$ of the participants); the second option corresponded to financial equilibrium (resources are just sufficient to cover expenses; 48.76\%); and the last two options corresponded to financial scarcity (resources are insufficient to cover expenses; $26.66 \%$; for a similar categorization, see Sommet et al., 2018).

We performed a series of preliminary tests to check the convergent validity of the measure. Financial scarcity was correlated with two objective and subjective economic strain indicators $(r s=|0.22|, p s<$ .001). Participants facing financial scarcity (vs. equilibrium/abundance) (1) were more exposed to material deprivation (not enough food, medicine, and cash) and (2) reported lower financial satisfaction. This provides evidence of the validity of the instrument (for the full results, see Supplementary Materials, including Table S2, pp. 7-8).

Country-year-specific income quintiles. Participants reported their income in only 45 of the 207 country-years, and the format varied from one country-year to another: Participants could report their household incomes using seven (Uganda, 2001) to 20 (South Africa, 2001) categories. To standardize the measure, we created a new variable based on the country-year-specific quintiles of income distribution. Specifically, we divided the participants from each country-year into five income category-based groups equally representing $20 \%$ of individuals.

Other social status-relevant variables. In addition to the common demographics (sex, age, and marital status), three social status-relevant measures served as control variables: subjective SES (from $1=$ lower class to $5=$ upper class), working status (not working vs. working), and education (no college degree vs. college degree).

\subsubsection{Outcome variables}

Self-rated health. Participants reported whether their current state of health was "very poor/poor" (7.21\%), "fair" (26.23\%), "good" (43.22\%), or "very good" (23.34\%).

Feelings of unhappiness. Participants reported whether their current state of mind was "very happy" (28.59\%), "rather happy" (52.46\%), "not very happy" (15.87\%), or "not at all happy" (3.08\%).

\subsection{Results}

\subsubsection{Preliminary analysis: relationship between financial scarcity and income quintile}

The overall correlation (Kendal's tau-b) between financial scarcity 
and country-year-specific income quintile was $-0.16, p<.001$. Although participants belonging to the bottom $20 \%$ were more likely to face financial scarcity than those in the other groups, approximately four-fifths of them experienced financial equilibrium or abundance; conversely, approximately half of participants belonging to the top $20 \%$ experienced financial scarcity (Table S3, left half).

Main analysis - the "what" question: The raw and incremental pooled effects of financial scarcity on self-rated health and feelings of unhappiness. Table 1 presents the full results and regression equation.

\subsubsection{Analytical strategy}

We used fixed-effects modeling (Allison, 2009). Fixed-effects regressions are similar to traditional regressions, except that they include cluster-based dummies. Specifically, our fixed-effects regression models included country-year-based dummies, which enabled us to discard all observed and unobserved country-year-based differences and, by implication, eliminate all potential between-country-year confounders. Therefore, our fixed-effects regression models produced coefficient estimates corresponding to the pooled within-country-year effects (e.g., the pooled effects of financial scarcity on self-rated health in Albania-1998, Albania-2002, Algeria-2002, ..., Zimbabwe-2012).

Because both of our outcomes had four ordered response categories, we used ordered logistic fixed-effects regression. ${ }^{2}$ For each outcome, we conducted the analysis in two stages. First, we estimated the raw pooled effect of financial scarcity within the 207 country-years (Model 1). Second, we estimated the incremental pooled effect of scarcity while controlling for income within the 45 country-years for which income was available (Model 2a) and for additional sociodemographic variables (Model $2 \mathrm{~b}$ ). ${ }^{3}$ The proportion of missing values ranged from $0.03 \%$ (sex) to $11.89 \%$ (subjective SES). We report the results using listwise deletion; however, following the current recommendations (Sidi and Harel, 2018), we repeated the main analysis using multiple imputation. The conclusions regarding our hypotheses remained the same (all $p s<.001$ ) (for the details, see Supplementary Materials, including Table S4, pp. 10-11).

\subsubsection{Financial scarcity and self-rated health}

In Model 1, the raw pooled within-country-year effect of financial scarcity was significant, $\chi^{2}(2, N=274,725)=4547.37, p<.001$. Participants facing financial scarcity were $15 \%$ more likely to report worse health than participants experiencing financial equilibrium and were 95\% more likely to report worse health than participants experiencing financial abundance (Fig. 1, left panel). Country-year-specific models revealed that the negative effect of financial scarcity was significant in $92.65 \%$ of the country-years (Table S1). In Models 2a-2b, the incremental pooled within-country effects of financial scarcity remained significant, $\chi^{2}(2, N=55,505)=568.95, p<.001$, and $\chi^{2}(2, N=44,582)$ $=223.64, p<.001$, respectively. This shows that financial scarcity explains variance over and above income quintile, and after we controlled for subjective SES and additional sociodemographic variables.

\subsubsection{Financial scarcity and feelings of unhappiness}

In Model 1, the raw pooled within-country-year effect of financial scarcity was significant, $\chi^{2}(2, N=276,694)=4184.86, p<.001$. Participants facing financial scarcity were $20 \%$ more likely than

\footnotetext{
${ }^{2}$ Preliminary likelihood ratio tests showed that the proportional odds assumption of the ordered logistic regression model held in the majority of country-years $(73.04 \%$ for self-rated health; $61.27 \%$ for feelings of unhappiness; Table S1).

${ }^{3}$ We conducted supplementary analysis testing the effects of the national financial scarcity rate on country-year-based life expectancy and suicide rate. These analyses-which were inconclusive-are reported in Supplementary Materials, p. 13.
}

participants experiencing financial equilibrium and $97 \%$ more likely than participants experiencing financial abundance to report strong feelings of unhappiness (Fig. 1, right panel). Country-year-specific models revealed that the negative effect of financial scarcity was significant in $88.73 \%$ of the country-years (Table S1). In Models 2a-2b, the incremental pooled within-country effects of financial scarcity remained significant, $\chi^{2}(2, N=58,689)=508.76, p<.001$, and $\chi^{2}(2, N=47,539)$ $=251.72, p<.001$, respectively. This again shows that financial scarcity explained variance over and above income quintile, and after we controlled for subjective SES and additional sociodemographic variables.

\subsection{Discussion}

There are two main takeaways from the WVS/EVS data. First, financial scarcity and income were only weakly correlated: one can face financial scarcity despite earning a high income; conversely, one can experience financial abundance despite earning a modest income. Second, financial scarcity had predictive utility in $\approx 90 \%$ of the countryyears (somewhat more than expected from the sensitivity analysis): Individuals experiencing financial scarcity (vs. abundance) in a given time/place were approximately twice as likely to suffer from reduced health or well-being (even after partialling out the variance explained by income and other status-relevant variable).

\section{Swiss Household Panel (SHP) data}

Second, we used the SHP data to test the effects of financial scarcity on self-reported health and feelings of depression over the life course. We also tested adverse life events as predictors of financial scarcity (the "when" question) and sense of control as a mechanism accounting for the detrimental longitudinal effects of financial scarcity (the "why" question).

\subsection{Method}

\subsubsection{Participants and procedure}

We pooled the responses from the SHP, a large annual national representative longitudinal survey based on random samples of Swiss households. Again, we retained only participants with nonmissing values for focal variables. Our final sample comprised 154,512 observations from 23,275 participants who completed the survey between 1999 and 2018 (52.97\% women; $M_{\mathrm{age}}=46.94, S D=18.54 ; 66.88 \%$ working; $15.89 \%$ with a university degree; $55.30 \%$ married/registered as partners; for the number of participants per year, see Table S6).

\subsection{Variables}

\subsubsection{Predictor variables}

Financial scarcity (1999-2018). As with the WVS/EVS data, participants reported whether their household (1) "saves money" $(54.81 \%$ of the participant-years - financial abundance), (2) "spends what it earns" (36.16\% - financial equilibrium), (3) "taps into its assets and savings" or "acquires debt" (9.03\% - financial scarcity).

As with the WVS/EVS data, we performed a series of preliminary tests to check the convergent validity of the measure. Financial scarcity was again correlated with a series of objective and subjective economic strain indicators $(r s=|0.18,0.40|, p s<.001)$. Households experiencing financial scarcity (vs. equilibrium/abundance): (1) were more exposed to material deprivation (e.g., not enough money to go to the dentist), were more likely to have payments in arrears, and did not earn enough money to make ends meet and (2) reported lower financial satisfaction, more difficulties in managing finances, and more economic worries. This provides further evidence of the validity of the instrument (for the full results, see Supplementary Materials, including Table S2, pp. 7-8).

Equivalized disposable income quintile (1999-2018). Participants 
Table 1

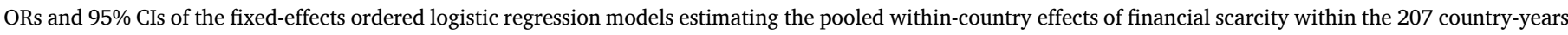
(Model 1), over and above income (Model 2), and controlling for sociodemographic variables (Model 3) (WVS/EVS).

\begin{tabular}{|c|c|c|c|c|c|c|c|c|c|c|c|c|}
\hline & \multicolumn{6}{|c|}{ Self-rated health $-Y$} & \multicolumn{6}{|c|}{ Feelings of unhappiness $-Y$} \\
\hline & \multicolumn{2}{|c|}{$\begin{array}{l}\text { Model } 1(n= \\
274,725)\end{array}$} & \multicolumn{2}{|c|}{$\begin{array}{l}\text { Model 2a }(n= \\
55,505)\end{array}$} & \multicolumn{2}{|c|}{$\begin{array}{l}\text { Model 2b }(n= \\
44,582)\end{array}$} & \multicolumn{2}{|c|}{$\begin{array}{l}\text { Model } 1(n= \\
276,694)\end{array}$} & \multicolumn{2}{|c|}{$\begin{array}{l}\text { Model 2a }(n= \\
58,689)\end{array}$} & \multicolumn{2}{|c|}{$\begin{array}{l}\text { Model 2b }(n= \\
47,539)\end{array}$} \\
\hline & OR & $95 \% \mathrm{CI}$ & OR & $95 \% \mathrm{CI}$ & OR & $95 \% \mathrm{CI}$ & OR & $95 \% \mathrm{CI}$ & OR & $95 \% \mathrm{CI}$ & OR & $95 \% \mathrm{CI}$ \\
\hline \multicolumn{13}{|c|}{ Financial scarcity-based measure } \\
\hline $\begin{array}{l}\text { Scarcity vs. equilibrium } \\
\text { (baseline) }-S e\end{array}$ & $0.87^{* * *}$ & $\begin{array}{l}{[0.86} \\
0.89]\end{array}$ & $0.88^{* * *}$ & $\begin{array}{l}{[0.85} \\
0.91]\end{array}$ & $0.85^{* * *}$ & $\begin{array}{l}{[0.82} \\
0.89]\end{array}$ & $1.20 * * *$ & $\begin{array}{l}{[1.17} \\
1.22]\end{array}$ & $1.18^{* * *}$ & $\begin{array}{l}{[1.13} \\
1.23]\end{array}$ & $1.23^{* * *}$ & $\begin{array}{l}{[1.17} \\
1.28]\end{array}$ \\
\hline $\begin{array}{l}\text { Scarcity vs. abundance } \\
\text { (baseline) }-S a\end{array}$ & $0.51^{* * *}$ & $\begin{array}{l}{[0.50} \\
0.52]\end{array}$ & $0.59 * * *$ & $\begin{array}{l}{[0.56} \\
0.61]\end{array}$ & $0.68 * * *$ & $\begin{array}{l}{[0.64} \\
0.71]\end{array}$ & $1.97 * * *$ & $\begin{array}{l}{[1.93} \\
2.01]\end{array}$ & $1.68^{* * *}$ & $\begin{array}{l}{[1.60} \\
1.76]\end{array}$ & $1.52^{* * *}$ & $\begin{array}{l}{[1.44,} \\
1.6]\end{array}$ \\
\hline \multicolumn{13}{|l|}{ Income quintile } \\
\hline $\begin{array}{l}\text { Bottom } 20 \% \text { vs. } 2 \text { nd quintile } \\
\text { (baseline) }-I_{1}\end{array}$ & & & $0.79^{* * *}$ & $\begin{array}{l}{[0.75} \\
0.83]\end{array}$ & $0.93^{* *}$ & $\begin{array}{l}{[0.88} \\
0.98]\end{array}$ & & & $1.18^{* * *}$ & $\begin{array}{l}{[1.13} \\
1.24]\end{array}$ & $1.08 * *$ & $\begin{array}{l}{[1.02,} \\
1.13]\end{array}$ \\
\hline $\begin{array}{l}\text { Bottom } 20 \% \text { vs. 3rd quintile } \\
\text { (baseline) }-I_{2}\end{array}$ & & & $0.73^{* * *}$ & $\begin{array}{l}{[0.69} \\
0.76]\end{array}$ & $0.93^{* *}$ & $\begin{array}{l}{[0.88} \\
0.98]\end{array}$ & & & $1.20 * * *$ & $\begin{array}{l}{[1.14} \\
1.26]\end{array}$ & 1.03 & $\begin{array}{l}{[0.97} \\
1.08]\end{array}$ \\
\hline $\begin{array}{l}\text { Bottom } 20 \% \text { vs. } 4 \text { th quintile } \\
\text { (baseline) }-I_{3}\end{array}$ & & & $0.62^{* * *}$ & $\begin{array}{l}{[0.59} \\
0.65]\end{array}$ & $0.86 * * *$ & $\begin{array}{l}{[0.81} \\
0.91]\end{array}$ & & & $1.29 * * *$ & $\begin{array}{l}{[1.23} \\
1.36]\end{array}$ & 1.05 & $\begin{array}{l}{[0.99} \\
1.11]\end{array}$ \\
\hline $\begin{array}{l}\text { Bottom } 20 \% \text { vs. } 5 \text { th quintile } \\
\text { (baseline) }-I_{4}\end{array}$ & & & $0.53^{* * *}$ & $\begin{array}{l}{[0.50} \\
0.56]\end{array}$ & $0.80^{* * *}$ & $\begin{array}{l}{[0.75} \\
0.85]\end{array}$ & & & $1.50^{* * *}$ & $\begin{array}{l}{[1.42,} \\
1.58]\end{array}$ & $1.14 * * *$ & $\begin{array}{l}{[1.07} \\
1.21]\end{array}$ \\
\hline \multicolumn{13}{|l|}{ Control variables } \\
\hline Sex $(+0.5=$ men $)-S$ & & & & & $1.14^{* * *}$ & $\begin{array}{l}{[1.1} \\
1.18]\end{array}$ & & & & & $1.14 * * *$ & $\begin{array}{l}{[1.1} \\
1.18]\end{array}$ \\
\hline Age (standardized) $-A$ & & & & & $0.65 * * *$ & $\begin{array}{l}{[0.63} \\
0.66]\end{array}$ & & & & & $1.11 * * *$ & $\begin{array}{l}{[1.09} \\
1.13]\end{array}$ \\
\hline $\begin{array}{c}\text { Marital status }(+0.5= \\
\text { partnered })-M\end{array}$ & & & & & $1.17^{* * *}$ & $\begin{array}{l}{[1.12} \\
1.21]\end{array}$ & & & & & $0.60^{* * *}$ & $\begin{array}{l}{[0.58} \\
0.62]\end{array}$ \\
\hline $\begin{array}{l}\text { Subjective SES (continuous) } \\
\quad-S C\end{array}$ & & & & & $0.79 * * *$ & $\begin{array}{l}{[0.77,} \\
0.80]\end{array}$ & & & & & $1.35^{* * *}$ & $\begin{array}{l}{[1.32,} \\
1.38]\end{array}$ \\
\hline $\begin{array}{l}\text { Working status }(+0.5= \\
\text { working })-W\end{array}$ & & & & & $1.30 * * *$ & $\begin{array}{l}{[1.25} \\
1.35]\end{array}$ & & & & & $1.05^{*}$ & $\begin{array}{l}{[1.01} \\
1.09]\end{array}$ \\
\hline $\begin{array}{l}\text { Education }(+0.5=\text { college } \\
\text { degree })-E\end{array}$ & & & & & $1.24 * * *$ & $\begin{array}{l}{[1.18,} \\
1.31]\end{array}$ & & & & & 1.01 & $\begin{array}{l}{[0.96} \\
1.06]\end{array}$ \\
\hline
\end{tabular}

Notes: The fixed-effects ordered logistic regression equation is logit $\left(\mathrm{P}\left(Y_{i t}<\mathrm{y}_{i t k}\right)\right)=B_{1} \times S e_{i c}+B_{2} \times S a_{i c}\left[\right.$ Model 1] $+B_{3} \times I_{1 i c}+\ldots+B_{6} \times I_{4 i c}\left[\right.$ Model 2a] $+B_{7} \times S_{i c}+B_{8}$ $\times A_{i c}+B_{9} \times M_{i c}+B_{10} \times S C_{i c}+B_{11} \times W_{i c}+B_{12} \times E_{i c}$ [Model 2b] $+\alpha_{c}+u_{i c}, k=1,2,3,4$ [categories of the outcome], $c=2,3, \ldots, 207$ [country-years], where $\left.\mathrm{P}\left(Y_{i t}<\mathrm{y}_{i t k}\right)\right)$ represents the cumulative probabilities of the outcome variable, $\alpha_{c}$ represents country-year fixed effects ( $c-1$ dummies), and $u_{i c}$ represents the error term; the difference between financial equilibrium and financial abundance was also significant across models for both self-rated health, $p \mathrm{~s}<.001$, and feelings of unhappiness, $p \mathrm{~s}<.001 ; n$ represents the overall number of within-participants; variations in the sample size are due to missing values; ** $p<.01,{ }^{* * *} p<.001$.

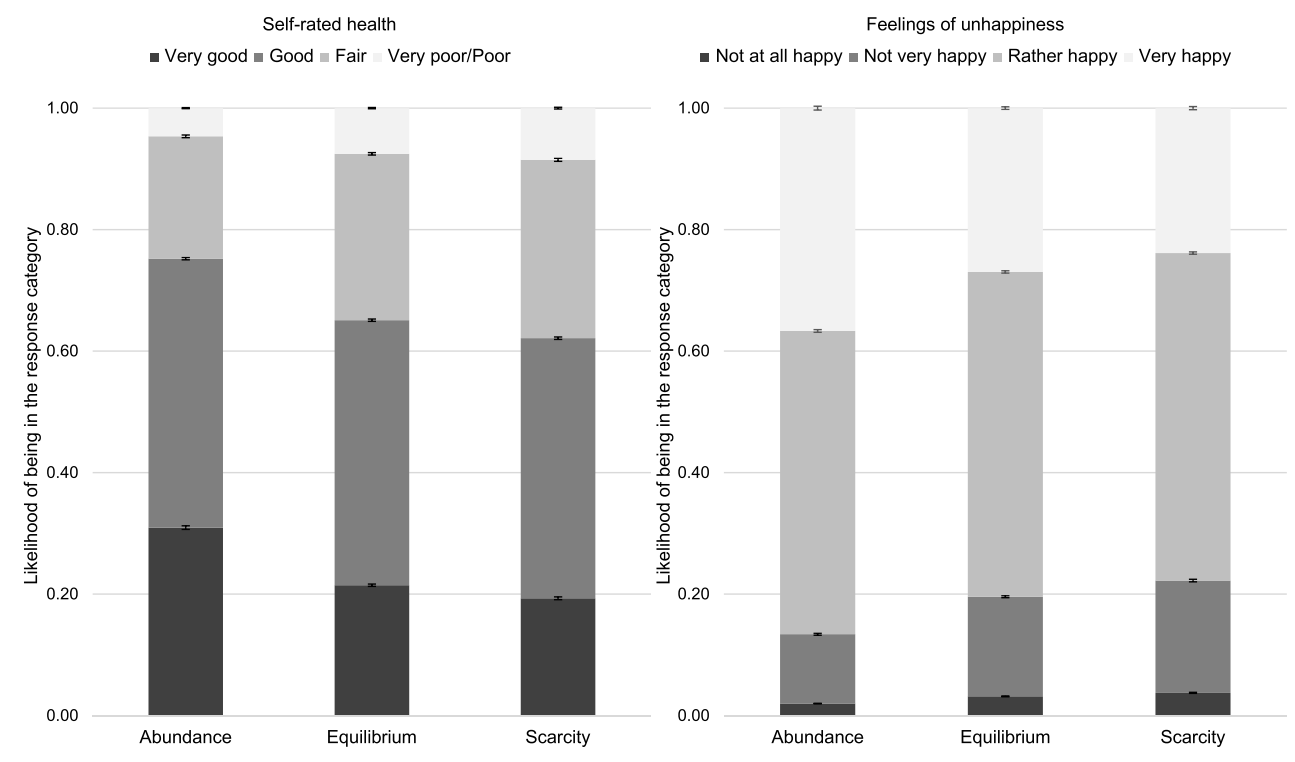

Fig. 1. WVS/EVS: Pooled within-country-year effect of financial scarcity on self-rated health (left panel) and feelings of unhappiness (right panel) depending on the category of financial scarcity within the 207 country-years. Note: Error bars represent the $95 \%$ CIs. 
reported their disposable income, which we equivalized to adjust for household size (equivalized disposable income = disposable income/ $\sqrt{ }($ household size)). To take annual inflation into account and to facilitate comparison with the WVS/EVS findings, we again created a new variable based on the year-specific quintiles of the equivalized disposable income distribution.

Other social status-relevant variables. The same two social statusrelevant measures used in the WVS/EVS data served as control variables: working and education. Subjective SES could not be included because it was not available for a sufficient number of years.

\subsubsection{Outcome variables}

Self-rated health (1999-2018). Participants reported their current states of health using a scale ranging from $1=$ not well at all to $5=$ very well $(M=4.05, S D=0.66)$.

Feelings of depression (1999-2018). Participants reported the frequency with which they "have negative feelings such as having the blues, being desperate, suffering from anxiety or depression," using a scale ranging from $1=$ never to $10=$ always $(M=2.04, S D=2.08)$.

\subsubsection{Other variables}

Adverse life events (2000-2018). Participants answered items assessing the occurrence (during the past year) of five adverse life events: (1) "illness, accident" (48.69\% of the participants over the course of the survey); (2) "illness, accident [of a] closely related person" (62.13\%); (3) "death of closely related person" (61.28\%); (4) "termination of a close relationship" (28.06\%), and (5) "conflicts with or among related persons" (30.99\%).

Sense of control (2009, 2012, 2015, 2018). Participants answered items assessing three components of sense of control: (1) predictability ("Often, it is not worth making plans, because too much is unpredictable" [reverse-coded], $M=5.57, S D=2.67$ ); (2) self-mastery ("I feel like I have little influence on the events of my life" [reversecoded], $M=6.23, S D=2.46$ ); and (3) self-efficacy ("I easily overcome unexpected problems," $M=6.72, S D=1.93 ; 0=$ completely disagree, 10 = completely agree).

\subsection{Results}

\subsubsection{Preliminary analysis: Relationship between financial scarcity and income quintile}

The correlation (Kendal's tau-b) between financial scarcity and income quintile was somehow stronger than that in the WVS/EVS, namely, $-0.31, p<.001$. However, the overlap between the two constructs remained rather small: Although participants belonging to the bottom $20 \%$ were more likely to face financial scarcity, approximately fourfifths of them experienced financial equilibrium or abundance; conversely, approximately one-fifth of participants belonging to the top $20 \%$ experienced financial scarcity (Table S3, right half).

Replication of the WVS/EVS findings - the "what" question: The raw and incremental longitudinal effects of financial scarcity. Table 2 presents the full results and regression equation.

Analytical strategy. In this analysis, we used fixed-effects linear panel modeling (Allison, 2009). Fixed-effects panel regressions are relatively similar to the fixed-effects regression used in the WVS/EVS data. The main difference is that these regressions include participant-based dummies, which enabled us to discard all observed and unobserved between-participant differences and, by implication, eliminate all potential time-constant between-participant confounders. In this analysis, our fixed-effects regression panel models produced coefficient estimates corresponding to the pooled within-participant effects over time (e.g., the pooled longitudinal effects of financial scarcity on self-rated

Table 2

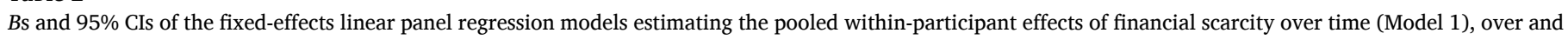
above income (Model 2a), and controlling for time-varying sociodemographic variables (Model 2b) (SHP).

\begin{tabular}{|c|c|c|c|c|c|c|c|c|c|c|c|c|}
\hline & \multicolumn{6}{|c|}{ Self-rated health $-Y$} & \multicolumn{6}{|c|}{ Feelings of depression $-Y$} \\
\hline & \multicolumn{2}{|c|}{$\begin{array}{l}\text { Model } 1(n= \\
154,462)\end{array}$} & \multicolumn{2}{|c|}{$\begin{array}{l}\text { Model 2a }(n= \\
141,772)\end{array}$} & \multicolumn{2}{|c|}{$\begin{array}{l}\text { Model 2b }(n= \\
141,728)\end{array}$} & \multicolumn{2}{|c|}{$\begin{array}{l}\text { Model } 1(n= \\
154,344)\end{array}$} & \multicolumn{2}{|c|}{$\begin{array}{l}\text { Model 2a }(n= \\
141,696)\end{array}$} & \multicolumn{2}{|c|}{$\begin{array}{l}\text { Model 2b }(n= \\
141,666)\end{array}$} \\
\hline & $B$ & $95 \%$ CI & $B$ & $95 \% \mathrm{CI}$ & $B$ & $95 \%$ CI & $B$ & $95 \% \mathrm{CI}$ & $B$ & $95 \% \mathrm{CI}$ & $B$ & $95 \% \mathrm{CI}$ \\
\hline Intercept & $4.00 * * *$ & $\begin{array}{l}{[3.99} \\
4.01]\end{array}$ & $3.99 * * *$ & $\begin{array}{l}{[3.97,} \\
4.00]\end{array}$ & $4.02 * * *$ & $\begin{array}{l}{[4.01,} \\
4.04]\end{array}$ & $2.23 * * *$ & $\begin{array}{l}{[2.20} \\
2.26]\end{array}$ & $2.28 * * *$ & $\begin{array}{l}{[2.24} \\
2.32]\end{array}$ & $2.23 * * *$ & $\begin{array}{l}{[2.18} \\
2.27]\end{array}$ \\
\hline \multicolumn{13}{|c|}{ Financial scarcity-based measure } \\
\hline $\begin{array}{l}\text { Scarcity vs. equilibrium } \\
\text { (baseline) }-S e\end{array}$ & $-.05^{* * * *}$ & $\begin{array}{l}{[-.06} \\
-.04]\end{array}$ & $-.05 * * *$ & $\begin{array}{l}{[-.06} \\
-.04]\end{array}$ & $-.04 * * *$ & $\begin{array}{l}{[-.05} \\
-.02]\end{array}$ & $.18^{* * *}$ & {$[.14, .21]$} & $.16^{* * * *}$ & {$[.13, .20]$} & $.14 * * *$ & {$[.10, .17]$} \\
\hline $\begin{array}{l}\text { Scarcity vs. abundance } \\
\text { (baseline) }-S a\end{array}$ & $-.06 * * *$ & $\begin{array}{l}{[-.07} \\
-.05]\end{array}$ & $-.06 * * *$ & $\begin{array}{l}{[-.07} \\
-.04]\end{array}$ & $-.05^{* * *}$ & $\begin{array}{l}{[-.07} \\
-.04]\end{array}$ & $.24 * * *$ & {$[.20, .27]$} & $.21 * * *$ & {$[.17, .24]$} & $.19 * * *$ & {$[.15, .22]$} \\
\hline \multicolumn{13}{|l|}{ Income quintile } \\
\hline $\begin{array}{l}\text { Bottom } 20 \% \text { vs. 2nd quintile } \\
\text { (baseline) }-I_{1}\end{array}$ & & & $-.02^{* * *}$ & $\begin{array}{l}{[-.03} \\
-.00]\end{array}$ & -.01 & $\begin{array}{l}{[-.02} \\
.00]\end{array}$ & & & $.04 * *$ & {$[.01, .07]$} & .02 & $\begin{array}{l}{[-.01} \\
.06]\end{array}$ \\
\hline $\begin{array}{l}\text { Bottom } 20 \% \text { vs. 3rd quintile } \\
\quad \text { (baseline) }-I_{2}\end{array}$ & & & $-.02^{* *}$ & $\begin{array}{l}{[-.03} \\
-.01]\end{array}$ & $-.01 *$ & $\begin{array}{l}{[-.03} \\
-.00]\end{array}$ & & & $.04 *$ & {$[.01, .08]$} & .02 & $\begin{array}{l}{[-.01} \\
.06]\end{array}$ \\
\hline $\begin{array}{l}\text { Bottom } 20 \% \text { vs. } 4 \text { th quintile } \\
\text { (baseline) }-I_{3}\end{array}$ & & & $-.02 * *$ & $\begin{array}{l}{[-.04} \\
-.01]\end{array}$ & -.01 & $\begin{array}{l}{[-.03} \\
.00]\end{array}$ & & & $.08^{* * * *}$ & {$[.05, .12]$} & $.06^{* *}$ & {$[.02, .10]$} \\
\hline $\begin{array}{l}\text { Bottom } 20 \% \text { vs. } 5 \text { th quintile } \\
\text { (baseline) }-I_{4}\end{array}$ & & & $-.03 * * *$ & $\begin{array}{l}{[-.05} \\
-.02]\end{array}$ & $-.02 *$ & $\begin{array}{l}{[-.03} \\
-.00]\end{array}$ & & & $.15^{* * *}$ & {$[.11, .19]$} & $.12^{* * *}$ & {$[.08, .16]$} \\
\hline \multicolumn{13}{|l|}{ Control variables } \\
\hline $\begin{array}{l}\text { Marital status }(+0.5= \\
\text { partnered })-M\end{array}$ & & & & & .00 & $\begin{array}{l}{[-.01} \\
.02]\end{array}$ & & & & & $-.22^{* * *}$ & $\begin{array}{l}{[-.26} \\
-.18]\end{array}$ \\
\hline $\begin{array}{l}\text { Working status }(+0.5= \\
\text { working })-W\end{array}$ & & & & & .01 & $\begin{array}{l}{[-.00} \\
.02]\end{array}$ & & & & & $-.04 * *$ & $\begin{array}{l}{[-.07} \\
-.02]\end{array}$ \\
\hline $\begin{array}{l}\text { Education }(+0.5=\text { college } \\
\text { degree })-E\end{array}$ & & & & & $.06^{* * *}$ & {$[.04, .09]$} & & & & & $-.09^{* * *}$ & $\begin{array}{l}{[-.16} \\
-.02]\end{array}$ \\
\hline Time (mean-centered) $-T$ & & & & & $-.01 * * *$ & $\begin{array}{l}{[-.01} \\
-.01]\end{array}$ & & & & & $.03^{* * * *}$ & {$[.03, .03]$} \\
\hline
\end{tabular}

Notes: The fixed-effects linear panel regression equation is $Y_{i t}=B_{0}+B_{1} \times S e_{i t}+B_{2} \times S a_{i t}[$ Model 1$]+B_{3} \times I_{1 i t}+\ldots+B_{6} \times I_{4 i t}[$ Model $2 \mathrm{a}]+B_{7} \times M_{i t}+B_{8}$

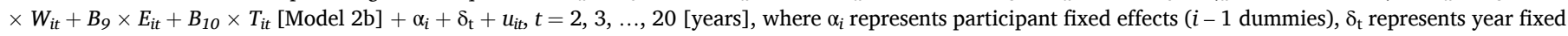

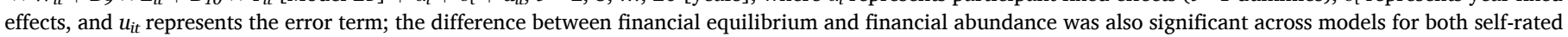

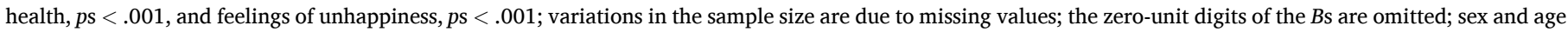
are not included in Model $2 \mathrm{~b}$ since sex is not a time-varying variable and age is collinear with time; ${ }^{*} p<.05, * * p<.01, * * * p<.001$. 
health in participant $1,2, \ldots, N)$. Fixed-effects regression panel models are considered among "the most powerful tools for studying causal processes using nonexperimental data" (Osgood, 2010, p. 380) because causality is often inferred from the pooled within-participant effects over time.

For each outcome, we again conducted the analysis in two stages. First, we estimated the raw pooled within-participant effect of financial scarcity over time (Model 1). Second, we estimated the incremental pooled effect of scarcity while controlling for income (Model 2b) and time-varying sociodemographic variables (Model 2c). The proportion of missing values ranged from $<0.01 \%$ (sex) to $8.22 \%$ (income quintile). As in the WVS/EVS data, we report the results using listwise deletion and repeated the main analyses using multiple imputation. The conclusions regarding our hypotheses remained the same (all $p s<.001$ ) (for the details, see Supplementary Materials, including Table S5, pp. 10, 12).

\subsubsection{Financial scarcity and self-rated health}

In Model 1, the pooled within-participant effect of financial scarcity was significant, $F(2,131,191)=48.25, p<.001$. When participants transitioned from financial equilibrium to scarcity, their health decreased by 0.05 points, and when they transitioned from financial abundance to scarcity, it decreased by 0.06 points (Fig. 2, left panel). In Models 2a-2b, the pooled within-participant effects of financial scarcity remained significant, $F(2,119,503)=37.23, p<.001$, and $F(2$, $119,467)=28.43, p<.001$, respectively. This shows that financial scarcity explains incremental variance over and above income quintile and after we controlled for additional time-varying sociodemographic variables. Repeating the analysis while treating income as a continuous measure (rather than using quintiles) led to the same conclusions (Table S7).

\subsubsection{Financial scarcity and feelings of depression}

In Model 1, the pooled within-participant effect of financial scarcity was significant, $F(2,131,080)=90.21, p<.001$. When participants transitioned from financial equilibrium to scarcity, their feelings of depression increased by 0.18 points, and when they transitioned from financial abundance to scarcity, their feelings of depression increased by 0.24 points (Fig. 2, left panel). In Models $2 \mathrm{a}-2 \mathrm{~b}$., the pooled withinparticipant effects of financial scarcity remained significant, $F(2$, $119,429)=61.96, p<.001$, and $F(2,119,405)=50.32, p<.001$, respectively. This again shows that financial scarcity explains incremental variance over and above income quintile and after we controlled for additional time-varying sociodemographic variables. Again, repeating the analysis while treating income as a continuous measure led to the same conclusions (Table S7).

\subsubsection{Robustness checks}

We performed two robustness checks. First, we repeated the analyses while using an alternative analytical approach: first-difference regression (Allison, 2009). In contrast to fixed-effects panel regression, which estimates the overall change over time, first-difference regression estimates the specific change between consecutive years. The detrimental effects of financial scarcity on health and feelings of depression were again significant, even after we controlled for income and/or additional time-varying demographics, $p s \leq .002$ (Table S8). These findings increase the level of confidence in the causal nature of the relationships.

Second, we repeated the main analyses while using two more objective health-related outcomes (number of doctor consultations in the past year; need for medication) and two alternative emotion-related outcomes (frequency of negative emotions; frequency of energy/optimism; Supplementary Materials, p. 17). When participants experienced financial scarcity (vs. equilibrium/abundance), they were more likely to consult a doctor, take more medication, report more negative emotions, and report less energy/optimism, even after we controlled for income and additional time-varying demographics, $p s \leq .045$ (Tables S9-S10). These findings increase the level of confidence in the reality of the phenomenon.

Extension of the WVS/EVS findings - the "when" question: Adverse life events as predictors of financial scarcity. We used fixedeffects multinomial panel regression to investigate whether the occurrence of adverse life events predicted financial scarcity over the life course. Table S11 presents the full results and regression equation.

We used a fixed-effects multinomial logit panel model because our outcome variable had three possible discrete responses (scarcity, equilibrium, and abundance). Participants whose financial scarcity statuses never changed over the course of the study could not be considered (because they did not show within-participant variance), leaving a sample of $n=110,216$ observations ( $71.33 \%$ of the full sample).

Three of the five adverse life events had significant withinparticipant effects, $p s<.001$. Participants were more likely to face financial scarcity rather than equilibrium/abundance in years when they were seriously ill or had an accident (14.48\%/17.21\% more likely, respectively), in years when they were separated from a serious partner $(22.29 \% / 46.42 \%)$, and in years when they experienced a conflict with close friends/relatives (14.04\%/27.00\%). However, participants were not more likely to face financial scarcity in years when a person close to
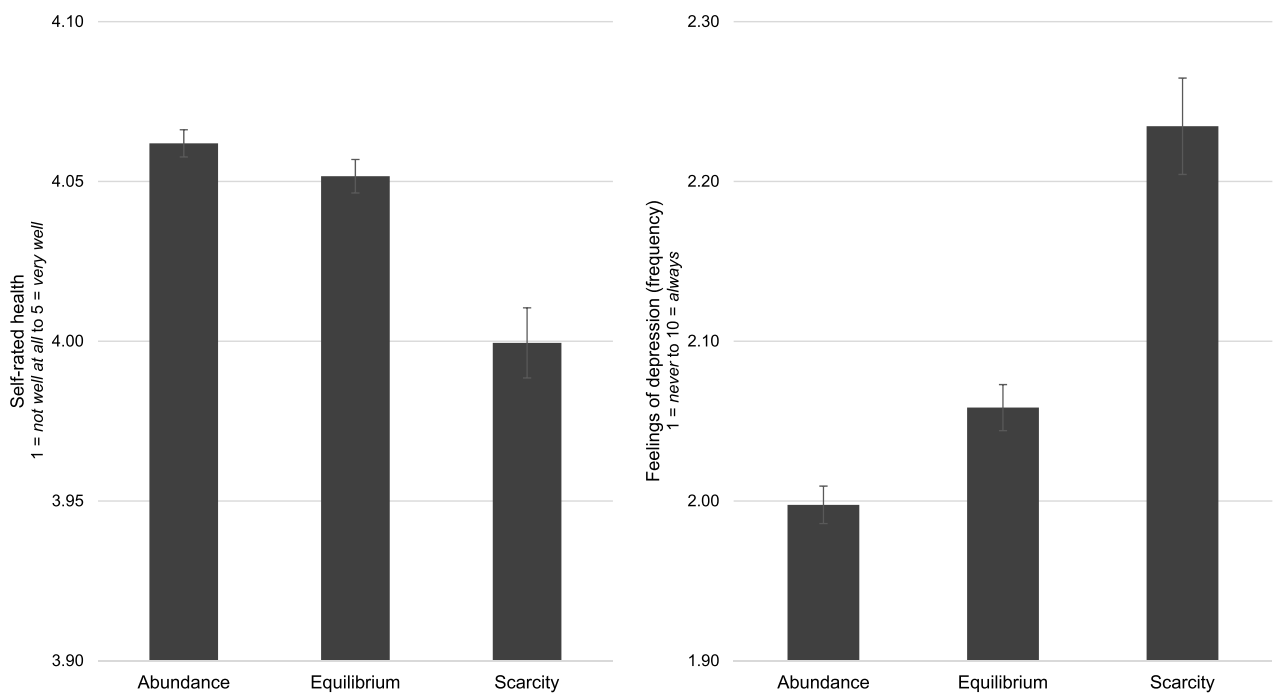

Fig. 2. SHP: Pooled within-participant effect of financial scarcity on self-rated health (left panel) and feelings of depression (right panel) depending on the category of financial scarcity. Note: Error bars represent the 95\% CIs. 
them became seriously ill, had an accident, or died. The results were the same when we controlled for income and additional time-varying demographics (for the full results, see Table S12).

Additional analysis revealed that only one of the five adverse life events (separating from a serious partner) had a significant withinparticipant effect on income when we controlled for financial scarcity and demographics (for the full results, see Table S13). This suggests that adverse life events may predict financial scarcity without necessarily involving a reduction in terms of income.

Extension of the WVS/EVS findings - the "why" question: The components of sense of control as mechanisms of the longitudinal effects of financial scarcity. We used fixed-effects linear regression panel mediation modeling to investigate whether the longitudinal effects of financial scarcity on self-rated health and feelings of depression were accounted for by a reduction in a component of sense of control. Table S14 presents the full results and regression equation.

Because sense of control was assessed only in 2009, 2012, 2015, and 2018 , we restricted our analysis to these years. In preliminary analysis, we tested the effect of financial scarcity on each component of sense of control while using a sequential Bonferroni correction procedure. Financial scarcity was not found to affect predictability or self-efficacy ( $p s \geq .270$ ); thus, we focused on one single component: self-mastery (Supplementary Materials, p. 24).

The mediation analysis led to three conclusions. First, the pooled within-participant effect of financial scarcity on self-mastery was significant, $F(1,19,825)=4.36, p=.013$. When participants transitioned from financial equilibrium to scarcity, their self-mastery decreased by 0.13 points, and when they transitioned from financial abundance to scarcity, their self-mastery decreased by 0.19 points ( $a$ path in Fig. 3). Second, the pooled within-participant effect of self-mastery was positive for self-rated health, $Z=5.79, p<.001$ ( $b 1$ path), and negative for feelings of depression, $Z=-12.89, p<.001$ ( $b 2$ path). Third, the indirect effects of financial scarcity via self-mastery (calculated using a Monte Carlo approach $\left[10^{7}\right.$ repetitions]) were negative for self-rated health, $Z s \geq-2.03, p s \leq .028$, and positive for feelings of depression, $Z s \geq 2.16, p s \leq .028 .4$ The results remained the same when we controlled for income and additional time-varying demographics, except that the total effect of financial scarcity on self-rated health became nonsignificant (for the full results, see Table S15).

\subsection{Discussion}

There are three main takeaways from the SHP data. First, we replicated the WVS/EVS findings using longitudinal data: Individuals experiencing financial scarcity over the course of the study suffered from reduced general and psychological health. Second, three adverse life events acted as predictors of financial scarcity: becoming seriously ill/ having an accident, separating from a serious partner, and experiencing a conflict with close friends/relatives. Third, one component of sense of control acted as a mechanism accounting for the detrimental longitudinal effects of financial scarcity: reduced self-mastery.

\section{General discussion}

\subsection{Brief summary of the findings}

First, addressing the "what" question, we found that financial scarcity was associated with reduced general and psychological health within most, if not all, countries around the world (WVS/EVS) and across the life course (SHP). Importantly, the effects of financial scarcity explained incremental variance over and above income, meaning that they were related to a different phenomenon than the income-health gradient. The effects of financial scarcity remained significant when controlling for subjective SES and/or other sociodemographic variables, indicating the robustness of the findings. Moreover, the effects of financial scarcity were replicated using alternative, often more objective measures (e.g., doctor consultation). Second, addressing the "when" question, we found that three adverse life events (illness, separation, family conflicts) predicted financial scarcity over time. Third, addressing the "why" question, we found that self-mastery, accounted for the longitudinal detrimental effects of financial scarcity on health.

\subsection{Contributions}

6.2.1. Both quantity and sufficiency of monetary resources are needed for a full account of socioeconomic inequality in health

Socioeconomic status refers to a social position traditionally defined by unequal access to monetary, cultural, social, and symbolic resources (Goudeau et al., 2017; Manstead, 2018). Accordingly, in the fields of psychology, sociology, and epidemiology lower-economic status individuals are often viewed as having a small amount of monetary resources, whereas higher-economic status individuals are viewed as having a larger amount of monetary resources (for a transdisciplinary review, see Matthews and Gallo, 2011). The present work suggests a shift in perspective: To understand socioeconomic inequality in health, one should consider not only an individual's quantity of monetary resources (income) but also the perceived sufficiency of these resources (financial scarcity).

The data-driven rationale for this shift in perspective is threefold. First, the quantity and sufficiency of monetary resources are distinct constructs. Although low income often entails financial scarcity, the majority of those in the bottom $20 \%$ do not report facing financial scarcity. Conversely, although high income often entails financial abundance, between $20 \%$ (SHP) and 50\% (WVS/EVS) of those in the top

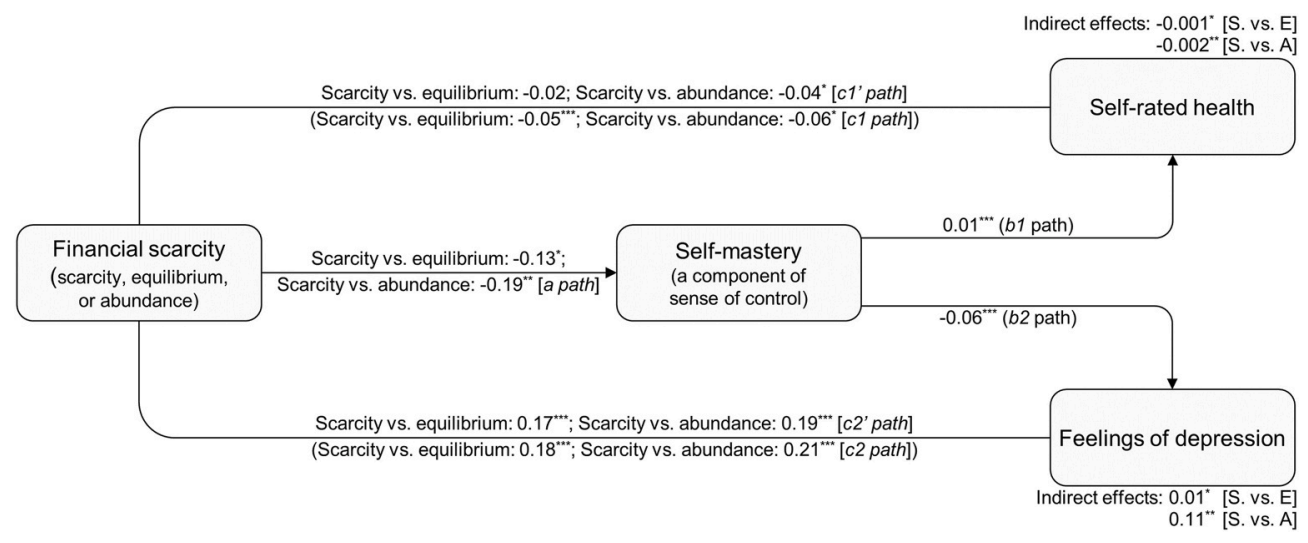

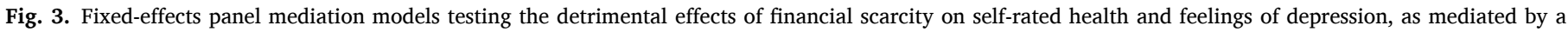
reduction in self-mastery. Note: ${ }^{*} p<.05,{ }^{*} p<<.01$, ${ }^{* * *} p<.001$. 
$20 \%$ report experiencing financial equilibrium or even scarcity. This suggests that having little is not the same as not having enough, echoing the words of Mullainathan and Shafir (2014), who claimed that individuals "with many wealth but many desires can in principle experience the same scarcity as another with less wealth (and fewer desires)" (p. 234).

Second, the quantity and sufficiency of monetary resources have additive effects. In both datasets, income and financial scarcity explained independent variance in health, demonstrating that financial scarcity captures something that income misses (and vice versa). This is likely because financial scarcity better reflects the active ingredient of economic vulnerability, whereas income may better reflect access to tangible goods and conditions. Therefore, it is possible that the effects of financial scarcity mainly (but not exclusively) operate via psychosocial pathways (e.g., economic anxieties, relative deprivation, and social isolation; Marmot and Wilkinson, 2001), whereas the effects of income mainly (but not exclusively) operate via material pathways (e.g., basic necessities, housing conditions, and access to amenities; Blázquez et al., 2014).

Third, the sufficiency of monetary resources has incremental effects over and above additional social status-relevant variables. In our datasets, the effects of financial scarcity remained substantive after we controlled for subjective SES and/or working status and education. This means that financial scarcity should be more systematically included among the existing conceptualizations/operationalizations of socioeconomic status (income, education, occupation, and subjective SES; for relevant research, see Kraus and Stephens, 2012), and one may wonder how financial scarcity compares to other socioeconomic indicators typically used in the fields of psychology (e.g., childhood SES, Griskevicius et al., 2011) or sociology (e.g., occupational prestige, Treiman, 2013) in predicting both health and nonhealth-related outcomes.

\subsubsection{A quantity-and-sufficiency perspective offers a more dynamic and comprehensive view of socioeconomic status}

First, a quantity-and-sufficiency perspective offers a more dynamic view of socioeconomic status. Whereas the quantity of monetary resources remains rather stable over time (OECD, 2018), the sufficiency of one's monetary resources can be affected by adverse life events in a more sudden and unexpected way. Interestingly, however, our finding shows that financial scarcity is only affected by self-based adverse life events (e. g., becoming ill), not by other-based adverse life events (e.g., having a significant other become ill). On the one hand, self-based adverse life events may drain not only psychological reserves, but also monetary reserves: Becoming ill may decrease labor participation and promote a transition toward financial scarcity (Haas, 2006), separating from a serious partner may increase housing costs and inhibit wealth accumulation (Bröckel and Andre $\beta, 2015$ ), and interpersonal conflicts may spill over or initiate financial stressors (Sturgeon et al., 2014). On the other hand, other-based adverse life events may be psychologically impactful without generating economic vulnerability.

Second, a quantity-and-sufficiency perspective offers a more comprehensive view of socioeconomic status. We observed that a reduction in self-mastery mediates the undesirable consequences of financial scarcity for feelings of depression over the life course (because the effects on self-rated health were descriptively smaller, we decided not to discuss them). In our view, this finding offers a glimpse into the so-called "scarcity mindset": A perceived decrease in monetary reserves over time (an objective situation of insufficiency) plagues one's mind, leading to thoughts that one's personal finances are becoming beyond one's control (the subjective experience of scarcity), which eventually increases stress and undermines psychological health. This view is consistent with an empirical study showing that the detrimental effects of financial strain on somatic symptoms are mediated by decreased feelings of mastery and personal control (Krause and Baker, 1992).

\subsection{Societal implications}

Our work also has societal implications. Legislators often define poverty in relation to a particular income-based threshold (for a review of the various definitions of poverty, see Hagenaars, 2017). For instance, the European Union regards persons with an equivalized disposable income after social transfer below $60 \%$ of the national median as being at risk of poverty (Eurostat, 2019). By extension, states often use such income-based thresholds to differentiate economically vulnerable from noneconomically vulnerable individuals and determine who should receive social welfare and who should pay income tax (Nelson, 2004). The goal of these redistributive policies is utilitarian: They aim to reduce economic inequality and maximize happiness among the majority of the population (for an empirical illustration, see Cheung, 2018).

The present research suggests that redistributive policies are likely suboptimal because income does not sufficiently capture the full extent of economic vulnerability; both the amount of monetary resources (income) and the sufficiency of monetary resources (financial scarcity) predict happiness. This means that redistributive policies are likely to "miss" economically vulnerable individuals whose earnings are above the social welfare threshold. For instance, some middle-income/highscarcity individuals may be economically vulnerable (e.g., when facing critical life events) but are taxed to finance redistributive transfers rather than be eligible to receive them.

\subsection{Limitations}

Two main limitations should be acknowledged.

\subsubsection{Measurement error}

First, most of our outcome variables were single-item measures, which is a source of measurement error. However, the findings were highly convergent across ten different indicators, and one of our robustness checks was a multiple-item measure (frequency of negative emotions). Although these two elements speak in favor of the reliability of the results, future studies using primary data should opt for multiitem scales.

\subsubsection{Causal inferences}

A second limitation is that the analysis of observational data cannot be used to draw causal inferences. However, we believe that causality should be evaluated in terms of a continuum of plausibility rather than a dichotomy (for a discussion of the taboo against causal inference in nonexperimental psychology, see Grosz et al., 2020). Arguably, the results obtained using the SHP longitudinal data are at the higher end of such a continuum and fixed-effects and first-difference regressions enabled us to approach causal inference (without formally establishing causality).

However, with this particular analytical strategy, the following two alternative explanations cannot be ruled out: (i) the presence of timevarying confounders (other than those we controlled for) and (ii) reverse causality (Hill et al., 2020). Regarding reverse causality, it is conceivable that certain life course trajectories reduce health, which in turn could make financial problems more likely and more worrisome. In our case, we believe that a bidirectional relationship is plausible. Becoming ill may cause one to fall into the financial scarcity trap (as demonstrated by the findings associated with our "when" question), and transitioning from financial equilibrium to scarcity can worsen health (as demonstrated by the findings associated with our "what" question), thereby aggravating the vicious circle of financial scarcity and poor health. This possibility is consistent with extant research documenting a bidirectional relationship between poverty and health (particularly mental health; for a review, see Ridley et al., 2020).

Likewise, it is conceivable that experiencing a lower sense of control at some point in one's life (i.e., lower self-mastery) reduces health, which in turn could make financial problems more likely and more 
worrisome. Here, we also believe that a bidirectional relationship is plausible, as a reduced sense of control may cause one to fall into the financial scarcity trap, while transitioning from financial equilibrium to scarcity can further decrease sense of control and damage health (for research examining this kind of dynamics, see Infurna et al., 2011).

\subsection{Conclusion}

Despite these limitations, our research shows that financial scarcity may provide a more accurate diagnosis of economic vulnerability than income alone. Specifically, we documented the following phenomenon: Some life events predict financial scarcity without entailing income loss; in turn, financial scarcity is associated with a lower sense of control, thereby acting as a negative predictor of general and psychological health over and above income. In our opinion, the implications of this phenomenon are threefold. First, our findings underscore the conceptual relevance of financial scarcity, which we believe offers a more dynamic (life course-based) and comprehensive (individual experience-based) view of socioeconomic vulnerability than perspectives currently available. Second, our findings underscore the operational relevance of financial scarcity, which has predictive utility over and above other social status-relevant variables and a place among the existing operationalizations of socioeconomic status. Third and finally, our findings underscore the practical relevance of financial scarcity, which may help social scientists and policymakers to obtain a better understanding of socioeconomic inequality in health across both the globe and the life course.

\section{Author contributions}

Nicolas Sommet: Conceptualization, Methodology, Software, Formal analysis, Investigation, Ressources, Data Curation, Writing Origial Draft; Visualization; Dario Spini: Conceptualization, Methodology, Writing - Reviewing and Editing, Supervision.

\section{Acknowledgement}

This work was funded by a SNSF Ambizione fellowship awarded to the first author (subside \#PZ00P1_185979).

\section{Appendix A. Supplementary data}

Supplementary data to this article can be found online at https://doi. org/10.1016/j.socscimed.2021.114607.

\section{References}

Adler, N.E., Boyce, T., Chesney, M.A., Cohen, S., Folkman, S., Kahn, R.L., Syme, S.L., 1994. Socioeconomic status and health: the challenge of the gradient. Am. Psychol 49 (1), 15-24.

Adler, N.E., Snibbe, A.C., 2003. The role of psychosocial processes in explaining the gradient between socioeconomic status and health. Curr. Dir. Psychol. Sci. 12, 119-123.

Agerbo, E., Sullivan, P.F., Vilhjalmsson, B.J., Pedersen, C.B., Mors, O., Børglum, A.D., Mortensen, P.B., 2015. Polygenic risk score, parental socioeconomic status, family history of psychiatric disorders, and the risk for schizophrenia: a Danish populationbased study and meta-analysis. JAMA Psychiatr. 72 (7), 635-641.

Allison, P.D., 2009. Fixed Effects Regression Models. SAGE publications, Thousand Oaks.

Blázquez, M., Cottini, E., Herrarte, A., 2014. The socioeconomic gradient in health: how important is material deprivation? J. Econ. Inequal. 12, 239-264.

Bolibok, P., 2018. The macroeconomic drivers of household debt-to-income ratio: an evidence from the OECD countries. Copernic. J. Finance Account 7, 29-41.

Bröckel, M., Andreß, H.-J., 2015. The economic consequences of divorce in Germany: what has changed since the turn of the millennium? Comp. Popul. Stud. 40, 277-312.

Carvalho, L.S., Meier, S., Wang, S.W., 2016. Poverty and economic decision-making: evidence from changes in financial resources at payday. Am. Econ. Rev. 106, 260-284.

Chambers, R., 1989. Editorial introduction: vulnerability, coping and policy. IDS Bull. $21,1-7$.
Cheng, G., Zhang, D., Ding, F., 2015. Self-esteem and fear of negative evaluation as mediators between family socioeconomic status and social anxiety in Chinese emerging adults. Int. J. Soc. Psychiatr. 61, 569-576.

Chetty, R., Stepner, M., Abraham, S., et al., 2016. The association between income and life expectancy in the United States, 2001-2014. J. Am. Med. Assoc. 315, 1750-1766.

Cheung, F., 2018. Income redistribution predicts greater life satisfaction across individual, national, and cultural characteristics. J. Pers. Soc. Psychol. 115 (5), 867-882.

Chipperfield, J.G., Newall, N.E., Perry, R.P., et al., 2012. Sense of control in late life: health and survival implications. Pers. Soc. Psychol. Bull. 38, 1081-1092.

Coleman, M., Rachet, B., Woods, L., et al., 2004. Trends and socioeconomic inequalities in cancer survival in England and Wales up to 2001. Br. J. Cancer 90, 1367-1373.

Cullati, S., Kliegel, M., Widmer, E., 2018. Development of reserves over the life course and onset of vulnerability in later life. Nat. Hum. Behav. 2, 551-558.

Dijkstra-Kersten, S.M., Biesheuvel-Leliefeld, K.E., van der Wouden, J.C., et al., 2015. Associations of financial strain and income with depressive and anxiety disorders. J. Epidemiol. Community Health 69, 660-665.

Eurostat, 2019. People at Risk of Poverty or Social Exclusion. https://ec.europa.eu/e urostat/web/products-datasets/-/t2020 50\&lang=en.

Evans, G.W., Kim, P., 2010. Multiple risk exposure as a potential explanatory mechanism for the socioeconomic status-health gradient. Ann. N. Y. Acad. Sci. 1186, 174-189.

FED, 2020. Consumer Credit Outstanding. https://www.federalreserve.gov/releases/g1 9/hist/cc hist sa levels.html.

Gallagher, M.W., Bentley, K.H., Barlow, D.H., 2014. Perceived control and vulnerability to anxiety disorders: a meta-analytic review. Cognit. Ther. Res. 38, 571-584.

Garrison, S.M., Rodgers, J.L., 2019. Decomposing the causes of the socioeconomic statushealth gradient with biometrical modeling. J. Pers. Soc. Psychol. 116, 1030-1047.

Glickman, L., Tanaka, J.S., Chan, E., 1991. Life events, chronic strain, and psychological distress: longitudinal causal models. J. Community Psychol. 19, 283-305.

Goudeau, S., Autin, F., Croizet, J.-C., 2017. Studying, measuring and manipulating social class in social psychology: economic, symbolic and cultural approaches. Int. Rev. Soc. Psychol. 30.

Griskevicius, V., Tybur, J.M., Delton, A.W., et al., 2011. The influence of mortality and socioeconomic status on risk and delayed rewards: a life history theory approach. J. Pers. Soc. Psychol. 100, 1015-1026.

Grosz, M.P., Rohrer, J.M., Thoemmes, F., 2020. The taboo against explicit causal inference in nonexperimental psychology. Perspect. Psychol. Sci. 15, 1243-1255.

Haas, S.A., 2006. Health selection and the process of social stratification: the effect of childhood health on socioeconomic attainment. J. Health Soc. Behav. 47, 339-354.

Hagenaars, A.J., 2017. The definition and measurement of poverty. In: Osberg, L. (Ed.), Economic Inequality and Poverty: International Perspectives. Routledge, London, England, pp. 148-170.

Hamilton, R.W., Mittal, C., Shah, A., Thompson, D.V., Griskevicius, V., 2019. How financial constraints influence consumer behavior: An integrative framework. J. Consumer Psychol. 29 (2), 285-305.

Hays, C., 2018. A global view of household debt. Report of the Bloom Economic Research Division. https://bloom.co/berd/a global view of household debt.pdf.

Hill, T.D., Davis, A.P., Roos, J.M., et al., 2020. Limitations of fixed-effects models for panel data. Soci. Perspect. 63, 357-369.

Infurna, F.J., Gerstorf, D., 2014. Perceived control relates to better functional health and lower cardio-metabolic risk: the mediating role of physical activity. Health Psychol. 33, 85-94.

Infurna, F.J., Gerstorf, D., Zarit, S.H., 2011. Examining dynamic links between perceived control and health: longitudinal evidence for differential effects in midlife and old age. Dev. Psychol. 47, 9-18.

Kahneman, D., Deaton, A., 2010. High income improves evaluation of life but no emotional well-being. Proc. Natl. Acad. Sci. U. S. A 107, 16489-16493.

Kang, S., 2016. Inequality and crime revisited: effects of local inequality and economic segregation on crime. J. Popul. Econ. 29, 593-626.

Karlamangla, A.S., Merkin, S.S., Crimmins, E.M., et al., 2010. Socioeconomic and ethnic disparities in cardiovascular risk in the United States, 2001-2006. Ann. Epidemiol. 20, 617-628.

Kraus, M.W., Stephens, N.M., 2012. A road map for an emerging psychology of social class. Soc. Personal. Psychol. Compass 6, 642-656.

Krause, N., Baker, E., 1992. Financial strain, economic values, and somatic symptoms in later life. Psychol. Aging 7, 4-14.

Lachman, M.E., Weaver, S.L., 1998. The sense of control as a moderator of social class differences in health and well-being. J. Pers. Soc. Psychol. 74, 763-773.

Lorant, V., Deliège, D., Eaton, W., et al., 2003. Socioeconomic inequalities in depression: a meta-analysis. Am. J. Epidemiol. 157, 98-112.

Manstead, A.S., 2018. The psychology of social class: how socioeconomic status impacts thought, feelings, and behaviour. Br. J. Soc. Psychol. 57, 267-291.

Marmot, M., Wilkinson, R.G., 2001. Psychosocial and material pathways in the relation between income and health: a response to Lynch et al. BMJ 322, 1233-1236.

Matthews, K.A., Gallo, L.C., 2011. Psychological perspectives on pathways linking socioeconomic status and physical health. Ann. Rev. Psychol. 62, 501-530.

Mullainathan, S., Shafir, E., 2014. Scarcity: the New Science of Having Less and How it Defines Our Lives. Picador, New York.

Nelson, K., 2004. Mechanisms of poverty alleviation: anti-poverty effects of non-meanstested and means-tested benefits in five welfare states. J. Eur. Soc. Pol. 14 (4), 371-390.

OECD, 2018. A Broken Social Elevator? How to Promote Social Mobility. OECD Publishing, Paris.

Osgood, D.W., 2010. Statistical models of life events and criminal behavior. In: Piquero, A.R., Weisburd, D. (Eds.), Handbook of Quantitative Criminology. Springer, pp. 375-396. 
Pearlin, L.I., Menaghan, E.G., Lieberman, M.A., et al., 1981. The stress process. J. Health Soc. Behav. 337-356.

Pearlin, L.I., Schieman, S., Fazio, E.M., et al., 2005. Stress, health, and the life course: some conceptual perspectives. J. Health Soc. Behav. 46, 205-219.

Präg, P., Mills, M.C., Wittek, R., 2016. Subjective socioeconomic status and health in cross-national comparison. Soc. Sci. Med. 149, 84-92.

Ridley, M., Rao, G., Schilbach, F., et al., 2020. Poverty, depression, and anxiety: causal evidence and mechanisms. Science 370.

Sahni, S., Talwar, A., Khanijo, S., et al., 2017. Socioeconomic status and its relationship to chronic respiratory disease. Adv. Respir. Med. 85, 97-108.

Sareen, J., Afifi, T.O., McMillan, K.A., et al., 2011. Relationship between household income and mental disorders: findings from a population-based longitudinal study. Arch. Gen. Psychiatr. 68, 419-427.

Shah, A.K., Mullainathan, S., Shafir, E., 2012. Some consequences of having too little. Science 338, 682-685.

Sidi, Y., Harel, O., 2018. The treatment of incomplete data: reporting, analysis, reproducibility, and replicability. Soc. Sci. Med. 209, 169-173.
Sommet, N., Morselli, D., Spini, D., 2018. Income inequality affects the psychological health of only the people facing scarcity. Psychol. Sci. 29, 1911-1921.

Spini, D., Bernardi, L., Oris, M., 2017. Toward a life course framework for studying vulnerability. Res. Hum. Dev. 14 (1), 5-25.

Sturgeon, J.A., Zautra, A.J., Okun, M.A., 2014. Associations between financial stress and interpersonal events: a daily diary study of middle-aged adults and their life circumstances. Psychol. Aging 29, 803-813.

Taylor, M., 2009. The Impact of Life Events on Financial Capability: Evidence from the BHPS. Financial Services Authority, London.

Tomm, B.M., Zhao, J., 2016. Scarcity captures attention and induces neglect: eyetracking and behavioral evidence. In: Papafragou, A., Grodner, D., Mirman, D., Trueswell, J. C. (Eds.), CogSci Pp. 1199-1204) (Austin).

Treiman, D.J., 2013. Occupational Prestige in Comparative Perspective. Elsevier.

Van Doorslaer, E., Masseria, C., Koolman, X., 2006. Inequalities in access to medical care by income in developed countries. CMAJ (Can. Med. Assoc. J.) 174, 177-183. 